\title{
COMUNICAÇÃO, CULTURA E GESTÃO EDUCACIONAL
}

Jō̄o Augusto Gentilini ${ }^{*}$

\begin{abstract}
RESUMO: O artigo objetiva, a partir das reflexões sobre a Indústria Cultural e a racionalidade dominante na sociedade industrial, feitas pelos filósofos da Escola de Frankfurt, discutir o modelo predominante de gestão das organizaçôes e a possibilidade de se pensar em uma teoria e um modelo de gestão fundamentado na teoria comunicativa proposta por aquela escola de pensamento e sua aplicação às organizações educacionais. Parte de alguns pressupostos para a formulação de uma teoria de gestão, como visão da organização, comunicação, poder e autoridade, na ótica da racionalidade técnica e instrumental para chegar, ao final, a um modelo de gestão em que estes mesmos pressupostos aparecem sob a racionalidade comunicativa.
\end{abstract}

Palavras-chave: Indústria Cultural, Racionalidade, Organização, Comunicação, Gestão Educacional.

O objetivo deste artigo é verificar se na discussão sobre Indústria Cultural e educação é possível encontrar elementos que possam fundamentar um modelo de gestão de organizaçôes educacionais. Desde os críticos anos 80 e com desdobramentos em toda a década posterior, tem-se colocado a necessidade de se rediscutir os modelos tradicionais de gestão e planejamento da educação. Verifica-se, dessa forma, o surgimento de uma diversidade de tendências que, embora não tenham ainda superado o plano teórico, apontam para a construção de modelos inovadores aparentemente mais adequados às transformaçóes que estão ocorrendo em todos os setores da sociedade.

Não tenho a pretensão de estabelecer uma "nova tendência" neste campo, mesmo porque necessitaria de dominar todo o saber acumulado em matéria de teorias e práticas de gestão e planejamento educacional. Manifesto, entretanto, a posição de que em matéria de gestão - como em todo

* Professor-Assistente Doutor do Departamento de Ciências da Educação da Universidade Estadual Paulista (Unesp/Campus de Araraquara).E-mail: gentilin@pcs.matrix.com.br 
o conhecimento humano - o saber acumulado é a base para a elaboração de novos saberes. As questóes sobre a Indústria Cultural, como já sabemos, foram expostas pela primeira vez nas reflexões dos filósofos frankfurtianos (Adorno \& Horkheimer, 1969), mas as relações com a gestão da educação ainda não foram suficientemente exploradas.

Tendo, pois, como referência teórica, as reflexões feitas pela Escola de Frankfurt sobre cultura, ciência, técnica e tecnologia na sociedade industrial contemporânea - irei me referir a elas como "Teoria Crítica" arrisco-me a fazer um "vôo" para estabelecer alguns liames entre aquelas reflexões e os esforços para se construir um modelo de gestão na área educacional. $\mathrm{O}$ vôo exige, preliminarmente, para ganhar alguma altura, o estabelecimento de alguns pressupostos.

Aceito, para início de discussão, que para se propor uma "teoria de gestão" é necessário que o discurso se apresente definindo pressupostos relativos à tomada de decisão, à visão e percepção dos integrantes da organização quanto ao meio em que atuam ou quanto às relaçóes externas da organização, à comunicação, ao poder e à autoridade. Estes pressupostos referem-se mais a uma "teoria de administração" do que de "gestão" em sentido amplo (Griffiths, 1986), mas servem-nos como ponto de partida. Não se está fazendo aqui, portanto, uma diferença conceitual entre "gestão" e "administração".

Diz-se que uma organização é o espelho de seu processo de tomada de decisão (ou vice-versa). Processos altamente centralizadores refletem organizações igualmente centralizadoras. Ao contrário, organizações democráticas são aquelas que possibilitam um razoável grau de participação e intervenção de seus membros nos processos decisórios. É possível, portanto, classificar as organizações, de acordo com seus processos decisórios, em democráticas, mais ou menos autoritárias, centralizadoras, burocráticas etc. Supõe-se, igualmente, que o estilo de liderança, direção ou autoridade acompanhem o modelo característico de tomada de decisão, embora alguns estudos em teoria organizacional, como os de Tanneubaun \& Schmidt (1979), tenham demonstrado que isto não é tão rigoroso, havendo "escalas" ou "níveis" de democracia, de centralismo ou de autoritarismo, conforme o problema a ser enfrentado que condicionaria o tipo de decisão a ser praticado.

$\mathrm{Na}$ perspectiva da Teoria Crítica, a sociedade industrial contemporânea, mais do que uma sociedade constituída de organizações, é uma sociedade constituída de organizações onde predominam processos mecânicos de decisão, fechando-se ao redor de seus membros um círculo de normas, regras, formalidades, rotinas que desestimulam sua participação ativa, 
crítica e criativa. As organizações, sejam aquelas onde ocorrem processos de produção de bens, sejam as que oferecem serviços à sociedade, operam dentro de uma racionalidade que é a racionalidade instrumental, na qual a estrutura predomina sobre os individuos que integram a organização que deles espera eficiência e resultados. Ao mesmo tempo, a estrutura funciona como um condicionante, uma determinação, da qual os membros da organização não escapam, não tendo, inclusive, precisa consciência da situação em que se encontram. A participação e a intervenção nos processos decisórios são puramente formais, ocorrendo dentro de instâncias e canais onde é possível controlá-las e limitá-las, sobretudo com relação às decisões de ordem estratégica, ou seja, aquelas que irão determinar o posicionamento futuro da organização em relação às outras organizações congêneres ou em relação à sociedade como um todo. Em última análise, esta estrutura que tende a ser altamente excludente em termos de intervenção consciente - ou profundamente includente se considerarmos a sua capacidade em obter a adesão incondicional e o envolvimento não-crítico de seus integrantes a seus objetivos - é por eles internalizada e pode parecer-lhes, inclusive, perfeitamente normal.

Organizações deste tipo tornaram-se generalizadas desde a extensão da lógica da eficiência, da produtividade e do trabalho ao conjunto da sociedade, como uma das dimensões das transformações do capitalismo industrial, que transformou a técnica e a ciência em forças produtivas (Habermas, 1983). A percepção que os indivíduos têm das organizações e entramos aqui no segundo pressuposto acima definido - é que elas são altamente operativas e úteis, responsáveis pela produção de bens e serviços para a sociedade. Eles a percebem, portanto, como organizações que satisfazem suas necessidades. Não lhes ocorre que estas necessidades são, em muitos casos, artificialmente produzidas, como não lhes ocorre que é mínima a condição de intervir no quanto, quais e para quem estes bens e serviços estão sendo produzidos ou se efetivamente correspondem às necessidades sociais e humanas. Internamente, a percepção dos membros da organização é que é perfeitamente natural e necessária à organização de trabalho no qual estão inseridos, mesmo que os torne isolados em suas especialidades, estanques em suas tarefas cotidianas, indiferentes aos fins últimos da organização e alienados quanto às suas conexôes com a totalidade social. Externa e internamente, os indivíduos estão convencidos - e os pensadores de Frankfurt mostraram como a ideologia dominante exerce um papel importante neste convencimento - de que é este o preço que devem pagar para continuarem a ter conforto material. 
Entrando aqui no terceiro pressuposto - a comunicação-, a Teoria Crítica tem muito a contribuir para a compreensão das organizações (e sua gestão) no contexto das sociedades capitalistas industriais desenvolvidas. É extremamente rico o conceito de comunicação para os frankfurtianos, porque, na condição de prática social, é através dela que se realiza a verdadeira interação humana e social e se reproduz a riqueza cultural da sociedade. É pelo cultivo, ampliação e manutenção de sua capacidade comunicativa que os seres humanos transcendem o isolamento, a fragmentação, o insulamento da divisão técnica e social do trabalho. O "mundo comunicativo", na perspectiva da Teoria Crítica, é parte do "mundo da vida” cuja dinâmica não é facilmente apropriada e conduzida pelas normas técnicas que movem a dinâmica produtiva e econômica. ${ }^{1}$

Contudo, nas organizaçōes nas quais a gestão é orientada pela racionalidade da eficiência e resultados, a comunicação aparece tão-somente como transmissão de ordens, determinações, normas e regulamentos. Ela é instrumental à manutenção e funcionamento de uma dada estrutura técnica que se sobrepõe aos indivíduos da organização e dos quais se espera que, instruídos e treinados sobre o que devem e não devem fazer, contribuam o máximo possível para o bom funcionamento da organização, considerandose que ela não pode perder seu lugar em uma sociedade altamente competitiva. A racionalidade organizacional é técnica, é instrumental e não é verdadeiramente comunicativa no sentido que lhe dão os frankfurtianos. A comunicação, enfim, é apenas mais um instrumento para manter a máquina administrativa em funcionamento, que reproduz internamente a racionalidade dominante na sociedade. Ela própria - como veremos logo a seguir - está contaminada por esta racionalidade.

Chegamos, enfim, aos dois últimos pressupostos: o poder e a autoridade. A perspectiva clássica de administração encara o poder e a autoridade como estando sempre e necessariamente juntos em uma organização, correspondentes às suas diversas instâncias hierárquicas e mantendo bem definidos os espaços e os níveis decisórios. Mas esta é uma perspectiva muito pobre de poder e autoridade, é uma visão mecânica que os considera como atributos da própria organização e, como tais, inquestionáveis. Os indivíduos que integram a gestão superior das organizações são os portadores do poder e da autoridade e os exercem como algo que está fora deles ou que é informado e comandado por uma dada estrutura organizacional. Da mesma forma, seus subordinados cumprem as determinações que lhes vêm de cima porque emanadas dos níveis superiores de gestão que não lhes compete questionar ou discutir. 
A Teoria Crítica demonstrou que o relacionamento hierárquico, o poder e a autoridade são necessários para a sobrevivência e a funcionalidade da organização, dentro da lógica econômica dominante, mas não necessariamente este modelo de relacionamento hierárquico, cuja origem é uma determinada organização racional do trabalho que se justifica técnica e cientificamente (como a organização taylorista). Por um lado, esclareceu que poder e autoridade poderiam ser exercidos, desde que livre e conscientemente aceitos por indivíduos enquanto agentes esclarecidos e informados sobre a sua finalidade e conseqüências. Por outro, denunciou que a mesma racionalidade que integrou a ciência e a tecnologia invadiu também o campo da interação comunicativa (a esfera pública, por excelência), direcionandoa para fins exclusivamente industriais, embora isto não seja definitivo, não seja completo e tenha que ser continuamente refeito face à possibilidade de os indivíduos recusarem tal invasão.

$\mathrm{O}$ fato de a esfera cultural e comunicativa ter sido invadida pela racionalidade industrial, com fins econômicos (daí, o termo "Indústria Cultural" criado por Adorno, referindo-se, neste caso, à cultura de massas), significa que os indivíduos são predispostos a aceitar formas políticas e ideológicas de dominação que resguardam, em última análise, poderosos interesses econômicos e que isto ocorre sem que tenham plena consciência disto - este é um tipo sofisticado e profundo de alienação.

As instituiçôes educacionais estão entre aquelas que atuam, predominantemente, na esfera pública, cultural da sociedade. E na perspectiva da Teoria Crítica, como notamos anteriormente, a cultura nas sociedades industriais é um campo onde se processou o estágio final da invasão da racionalidade técnica e instrumental, largamente facilitada pelos aperfeiçoamentos tecnológicos no campo da comunicação - os chamados veículos de comunicação de massa. Isto quer dizer que a dominação penetrou a subjetividade dos indivíduos, incutindo-lhes conformismo e empobrecendo, se não neutralizando, sua capacidade crítica.

Nunca se viu, como atualmente nas sociedades industriais, uma invasão tão grande das instituiçōes educacionais, notadamente das escolas, pela chamada "Indústria Cultural" que, pretensamente, tenta substituir, com base nas novas formas de comunicação (TV, rádio, cinema, imprensa, publicidade e, atualmente, computadores) as formas convencionais e tradicionais de se educar e ensinar, ganhando a cada dia novos espaços. Tudo indica que, nas próximas décadas, as organizaçôes educacionais estarão disputando espaço com esta indústria o papel de instituição de produção e transmissão de ciência e cultura e de formação de comportamentos e mentalidade. Isto já está ocorrendo, como foi denunciado na produção filosófica dos pen- 
sadores frankfurtianos, em detrimento da dimensão verdadeiramente comunicativa, crítica, social e humanamente enriquecedora (dentro de uma práxis histórica de transformação social) e em favor dos objetivos e interesses da Indústria Cultural.

Neste contexto, os gestores se colocam como mediadores de grande importância para viabilizar, dentro das organizaçóes educacionais, este domínio crescente da subjetividade dos jovens educandos pela Indústria Cultural. E o fazem, inicialmente, à medida que assimilam e reproduzem internamente as práticas de gestão características da racionalidade dominante (e reforçam a cultura organizacional correspondente); depois, à medida que se tornam indiferentes ou não dão a devida importância ao que está, efetivamente, ocorrendo no processo educativo e, por último, quando se preocupam somente com a transmissão conteudística, formal e mecânica dos conhecimentos, facilitada pela "tecnologia educacional". Dito de outra forma, quando a prática de gestão preocupa-se mais com os aspectos técnicos processuais da organização e da transmissão de saberes do que com os seus aspectos substantivos, formativos e institucionais - justamente o que dá sentido e justifica socialmente a organização e a educação em sentido amplo - mais um espaço importante da sociedade, o espaço da educação, tornouse vulnerável à invasão da Indústria Cultural e o campo comunicativo, em seu sentido humano e social, perdeu mais uma batalha.

Arriscamo-nos, nas reflexões anteriores, a enveredar por um beco sem saída e a cair em um certo pessimismo com relação à possibilidade de criarmos uma outra cultura organizacional, baseada na dimensão cultural e comunicativa, se aceitamos que não há, nas condições históricas atuais, alternativas diferentes de gestão das organizações que sejam de resistência à industrialização da cultura e seu mais caro instrumento, a educação. Entretanto, um olhar mais atento para os argumentos centrais da Teoria Crítica estimula-nos a pensar em alternativas, a partir das próprias categorias de análise que ela utiliza para analisar a sociedade industrial. Trata-se da própria categoria da "racionalidade", que é utilizada sobretudo por Habermas (1983), que cunhou a expressão "ação-racional-com-respeito-a-fins", um tipo de ação predominante nas sociedades industriais, de natureza prática, utilitária e objetiva, dando à racionalidade um caráter essencialmente técnico e instrumental, do qual se serve a Indústria Cultural.

Para opor-se a esta racionalidade, que opera no plano tecnológico e econômico-produtivo e que informa a atuação das organizações e dos indivíduos em geral, Habermas afirmou a possibilidade de despertar (já que ela está, devido às atuais circunstâncias históricas, apenas momentaneamente inerte) um outro tipo de racionalidade, cuja base está na dimensão 
psicológica, subjetiva, simbólica e cultural em sentido amplo dos indivíduos. No plano da "comunicabilidade", está a dimensão mítica, estético-artística e, de certa forma, "irracional" dos indivíduos, no sentido de algo que não se pode prever, controlar ou manipular tecnologicamente, embora o possa ideologicamente. É este o plano, por excelência, da subjetividade, do sentimento, das emoçôes, enfim, das relações sociais e humanas dos indivíduos. É o campo, por exemplo, que pode ser profundamente tocado por uma autêntica obra de arte.

Para os objetivos deste artigo - estamos tentando vincular estas reflexões a uma proposta de gestão - é possível considerar que, enquanto a racionalidade técnico-instrumental tenderia a privilegiar os objetivos da organização e de sua estrutura técnico-normativa em detrimento dos indivíduos que a integram, a racionalidade comunicativa, agindo no campo cultural, daria ênfase aos objetivos dos individuos e sua subjetividade. A gestão, desta forma, teria que escolher, na sua tarefa de mediar produtivamente essa relação organização-indivíduo, entre "administrar" os conflitos que eventualmente pudessem surgir entre eles, colocando em risco a própria organização ou tentar fazê-lo, mas em benefício dos interesses dos indivíduos. É oportuno lembrar, inclusive, que na história das teorias administrativas e organizacionais, o modelo clássico de gestão (ou de gerência), representado por Taylor e seus discípulos, não admitia em hipótese alguma a possibilidade de conflito de interesses entre os indivíduos e as organizações no local de trabalho, tendo desenvolvido um aparato de controles, normas e regulamentos que expressava e, ao mesmo tempo, garantia a rígida divisão do trabalho, sobretudo entre o planejamento e a execução das tarefas. Tão logo este modelo esgotou-se, tentou-se sua substituição por um outro que levava em consideração as relações humanas e informais no local do trabalho (com base nas pesquisas de Elton Mayo e seus associados), mas que, de qualquer maneira, tinha também por objetivo evitar a ocorrência de conflitos e aumentar a produtividade no trabalho. São casos típicos de uma escolha feita pela gestão em favor da organização de forma unilateral, para atender ao objetivo de aumento da produtividade.

O modelo clássico de gestão e o modelo que lhe seguiu podem ser facilmente enquadrados na racionalidade instrumental, de natureza positivista, na perspectiva das ciências gerenciais e administrativas. Os problemas das organizações devem ser tratados pelos gestores sempre como sendo causados por "indivíduos" que não se ajustam a elas e que, portanto, precisam ser afastados de seu meio. Mesmo que, no caso do segundo modelo, sejam realçadas as relações humanas, elas devem ser "administradas" pelos gestores para que se tire o maior proveito possível delas em benefício das 
organizações. Ambos os modelos têm em comum o fato de impedir que se estabeleça um clima organizacional que facilite a estruturação de relações humanas e sociais dentro da organização, de forma coletiva e enriquecedora para cada um e para todos os indivíduos, e que isto possa afetar, por exemplo, o processo decisório.

Ora, é exatamente isto o que ocorre na sociedade como um todo, se considerarmos que as estratégias utilizadas pela Indústria Cultural são, exatamente, no sentido de homogeneizar gostos, comportamentos, para facilitar a circulação dos "produtos culturais" que são, apenas, mais um tipo qualquer de mercadoria (música, pintura, filmes, fotos etc.). A ideologia expressa pelos representantes da Indústria Cultural é a de que cada individuo tem "a liberdade de adquirir no mercado o bem cultural que lhe interessar". Mas, no momento em que são oferecidos apenas bens culturais tecnicamente reproduzidos e padronizados (a base da cultura de massa), ela oculta o fato real da massificação, ou seja, da perda da subjetividade de cada indivíduo, deixando-o pouco disponível a desenvolver, através da esfera cultural, autênticas relações humanas e sociais, base para o início de uma ação coletiva cuja dinâmica está na relação dialética entre o subjetivo e o objetivo. Este fato ocorre, também, nas organizaçôes educacionais que são geridas, de qualquer forma, sob estes mesmos valores, ou seja, os valores imperantes na sociedade industrial, de consumo e de massas.

Trata-se, pois, de construir um modelo de gestão cujas estratégias potencializem a outra racionalidade ou que operem sob valores referentes à comunicabilidade e à subjetividade. Será que poderíamos encontrar, entre os elementos que constituem a forma e o conteúdo da comunicação humana - visto que é neste campo que a racionalidade instrumental tem tentado penetrar e o tem conseguido com grande êxito - algum no qual se possa desenvolver estratégias opostas ou, pelo menos, de resistência? Os filósofos de Frankfurt entenderam que era no próprio campo estético que poderia ser desenvolvida uma ação de recuperação dos espaços invadidos pela racionalidade instrumental. Criticaram, inclusive - e a crítica já apontava o caminho -, o fato de a Indústria Cultural ter transformado o momento de se usufruir da arte e do lazer em uma oportunidade de se auferir mais lucros, oferecendo opções que não representavam uma satisfação completa, mas sempre um consumo passivo e manipulado. Adorno, inclusive, demonstrou que a organização do campo do lazer e da arte acaba sendo, apenas, mais um prolongamento da organização do trabalho. Este perdera seu sentido como espaço de criação e, portanto, de afirmação da subjetividade. 
Creio que a primeira iniciativa para se construir um modelo alternativo de gestão deva partir de um posicionamento teórico no campo das teorias de gestão. Os pressupostos a partir dos quais foi feita a análise da racionalidade, atualmente hegemônica nas organizaçôes e que se estendeu ao campo educacional, podem ser, mais uma vez, este ponto de partida para o oferecimento deste modelo alternativo. Assim, é evidente que a opção dos gestores, no caso dos processos de tomada de decisão em um modelo alternativo de gestão, deve se situar fundamentalmente no campo democrático. A aceitação de que tomar decisões é um processo e, mais do que isso, um processo coletivo e não pessoal ou subjetivo, garantido por uma prerrogativa de quem, por imperativo bucrocrático, ocupa cargos nas organizaçóes, é fundamental para se construir um modelo de gestão fundado na racionalidade cultural e comunicativa.

Na história das teorias de gestão, a percepção de que os processos de decisão eram altamente centralizadores, lentos e burocráticos surgiu a partir da percepção da necessidade de adequar o modelo organizacional das grandes corporaçōes industriais em uma fase de luta por mercados e, consequentemente, de acirrada competição e necessidade de obter maior produtividade dos trabalhadores (Lodi, 1982). Até então, a teoria de gestão hegemônica não se atrevia a propor processos democráticos de decisão nas organizaçôes industriais, ao contrário, proporcionava a justificativa "científica" para que os métodos centralizadores e autoritários fossem mais sofisticados e eficientes. Quem primeiro explicitou de forma teoricamente bem elaborada a amplitude dos níveis decisórios nas pequenas, médias e grandes empresas, como sabemos, foi Henry Fayol, na sua teoria de "amplitude de campo", e seu propósito foi, a partir dela, definir a extensão da autoridade dentro de uma organização (Fayol, 1986).

A "descoberta" da necessidade de se ampliar o campo decisório, portanto, nas clássicas teorias de gestão, não significou que seus proponentes desejavam, convictamente, que houvesse democracia nas organizaçōes. $\mathrm{O}$ objetivo era integrar de forma mais efetiva os trabalhadores e funcionários aos objetivos da empresa, para que os produtos e serviços de melhor qualidade possibilitassem melhor posição no mercado em relação a seus concorrentes. O estabelecimento de processos democráticos, na perspectiva da racionalidade comunicativa, dependeria de implantar-se na organização espaços de encontro, integração e discussão aberta e livre entre seus integrantes, após abrir-lhes as informaçōes estratégicas da própria organização, inclusive para melhor fundamentação das decisōes coletivamente tomadas. Isto pode implicar, em alguns tipos de organização, no abandono do tradicional "organograma" e na adoção de uma estrutura organizacional que 
privilegie as relações horizontais entre seus integrantes. Não é algo que se possa implantar da noite para o dia, mas acredito que é impossível trilharse um caminho que não seja este, se se deseja realmente a adoção de uma gestão democrática. Nas condições de um modelo vertical e piramidal de organização, seria impossível a adoção de verdadeiros processos democráticos.

Em segundo lugar, uma teoria de gestão com base na racionalidade cultural e comunicativa deve admitir que dentro das organizaçôes haja um amplo debate sobre a posição da organização na sociedade como um todo e, principalmente, a consciência crítica da qualidade das relaçóes sociais nela predominantes, ou seja, restabelecer a percepção da conexão da organização com o todo social. Este debate é fundamental, na medida em que proporciona, de forma gradativa, o que eu denominaria um processo de "desfocalização", que vai de encontro ao que a ideologia dominante tenta implantar na sociedade atual que é deslocar o foco do geral para o particular, exatamente para que a história de sucessos e fracassos da organização - e dos indivíduos que a compõem - se explique em termos individuais e organizacionais e não em termos sociais.

Em terceiro lugar, no que diz respeito ao poder e à autoridade, uma teoria de gestão deve considerar que os integrantes da organização não são peças de uma engrenagem ou portadores ambulantes de uma estrutura morta. São seres sociais e atores políticos, circunstancialmente atuando no espaço restrito de seu departamento ou de sua seção, mas cada qual com um imenso potencial de ação. O sentimento de que estão sendo manipulados ou de que as decisões tomadas pelas instâncias superiores da organização expressam, por exemplo, os interesses de um grupo em luta por poder, prestígio ou maior participação nos benefícios da organização, os condiciona a desenvolver uma atitude de resistência que dificulta o estabelecimento de um ambiente cooperativo de trabalho. $\mathrm{O}$ reconhecimento de que em qualquer lugar onde se estabeleçam relações de hierarquia há manifestações de poder não é a questão fundamental. A questão fundamental é que este poder seja legítimo, ou seja, que a maioria contribuiu para a sua formação, com a consciência de que deve ser utilizado em benefício da organização como um todo e do alcance de seus objetivos enquanto organização. $\mathrm{O}$ estabelecimento de poder com base na discussão implica, portanto, consenso fundamentado em acordos e negociações.

Quanto à comunicação, creio que se deva promover uma completa reformulação de seu conceito tradicional de "transmissão de informaçôes", em que se pressupõe um emissor e um receptor passivo, como nos modelos clássicos de gestão. Se considerarmos que os integrantes de uma organização são atores, a comunicação deve considerar que há, por parte deles, formas 
de reinterpretação de significados que não estão limitadas aos padrões da racionalidade técnica, mas também - e com mais ênfase - aos padróes simbólicos, culturais, originados das experiências pessoais de cada ator, trazidas de fora da organização e/ou constituídas nas relações com outros atores dentro da organização. Gestores formados na perspectiva de modelos clássicos tendem a pensar que suas "ordens e determinações", por estarem supostamente baseadas em critérios técnicos, dificilmente deixarão de ser compreendidas ou interpretadas como tal e serão naturalmente acatadas e cumpridas. Menosprezam a capacidade de reinterpretação por outros critérios $e$ valores que não os técnicos e normativos, ou seja, desconsideram que verdade e objetividade são produtos humanos (Giroux, 1986).

A propósito, a Teoria Crítica, proporcionando-nos uma base filosófica para o questionamento da racionalidade instrumental ou do "agir estratégico" e a alternativa do "agir comunicativo", abriu-nos a possibilidade de pensar a comunicação nas organizações muito além de seu aspecto formal e ritualístico. Estou pensando em uma gestão que valorize os aspectos substantivos da linguagem ou que faça da comunicação verbal (mais do que aquela feita por intermédio da escrita fria e impessoal dos memorandos, ordens e despachos) o veículo por excelência de contatos entre as diversas instâncias hierárquicas e entre os integrantes da organização. É óbvio que uma prática deste tipo deve sofrer limitaçôes em virtude do gigantismo das organizaçôes, mas isto pode ser equacionado na medida em que o modelo de gestão a ser implantado seja aquele que valorize as relações horizontais e não as verticais, como foi dito anteriormente. ${ }^{2}$

Uma teoria de gestão alternativa, portanto, deve aceitar que as organizações se justifiquem enquanto instrumentos inventados pelo homem para promover o bem-estar da sociedade sob todos os aspectos - a satisfação de necessidades materiais, culturais, simbólicas etc. - e não o sofrimento, a opressão e o desconforto sociais. Criar um ambiente organizacional que não se limite ao ambiente de "segredos" que caracteriza uma gestão clássica - fonte constante de desconfiança - é uma forma de respeito à subjetividade, à criatividade, à inovação consentida, enfim, à autonomia dos integrantes da organização. É evidente que a criação de um clima organizacional efetivamente comunicativo dependerá de acordos e consensos que sejam claramente estabelecidos entre os diversos níveis e instâncias hierárquicas da organização, para que seus objetivos últimos sejam resguardados.

A Indústria Cultural, tal como exposta pelos frankturtianos, não teria a mesma eficácia ideológica se a sociedade fosse constituída de atores conscientes, críticos, capazes de reelaborar o volume de informações que lhes é oferecido de forma limitada, dirigida e massificada, através de veículos 
de comunicação de massa cada vez mais aperfeiçoados. Não teria a mesma eficácia, para impedir o surgimento de uma contra-ideologia que tenha em seu horizonte a emancipação humana e social, a preservação de subjetividades (e não de subjetivismos), a solidariedade, a convivência e a construção de relações que não sejam as da sociedade de consumo.

Neste sentido, sem superestimar a capacidade de resistência e ação das organizaçôes educacionais, podemos afirmar que elas estão estrategicamente melhor situadas em relação às outras organizações, para iniciar uma mudança que, necessariamente, deve começar no âmbito de suas relações internas de poder e autoridade, tais como estão estruturadas; no âmbito da organização do trabalho educativo e, logicamente, do modelo de gestão que o viabiliza. Isto implica pensar modelos de gestão inovadores que devem, entretanto, ser teoricamente justificados e antecedidos pela reflexão em torno de uma teoria de gestão, na qual a questão da racionalidade seja o ponto central da própria reflexão.

Uma teoria de gestão inspirada nas reflexões da Teoria Crítica, por caminhar justamente na direção do que é mais forte e presente em uma sociedade de consumo e de comunicação de massas - a racionalidade instrumental - tem um significativo potencial teórico para fundamentar um modelo inovador de gestão. As estratégias possíveis para a sua implantação, entretanto, não dependeriam exclusivamente do voluntarismo bem-intencionado dos gestores, mas, obviamente, da análise e consideração de todo um contexto político, social, político, ideológico e cultural em sentido amplo e, particularmente, da posição estratégica das instituições e organizaçôes educacionais neste contexto. Mas isto, sem dúvida, seria objeto de uma outra reflexão. ${ }^{3}$

\section{Notas}

1. Ao concluir este artigo, tomei conhecimento do livro Gestão Comunicativa: maximizando criatividade e racionalidade - uma política de Recursos Humanos a partir da Teoria de Habermas, de Gustavo Luis Gutierrez, publicado pela Qualitymark Editora (1999). O autor, utilizando como referencial teórico o pensamento de Habermas, explora as possibilidades de uma gestão comunicativa nas organizaçóes, embora em uma direção diferente deste artigo.

2. Embora não originada dos frankfurtianos, mas, ao meu ver, muito útil para se pensar em uma gestão que valorize e dê nova dimensão à comunicação verbal entre os integrantes de uma organização, a produção teórica dos filósofos da linguagem pode se constituir em uma excelente contribuição. Refiro-me, aqui, aos estudos de Austin, Quine, Strawson, Chomsky e outros, mas notadamente Austin, que desenvolveu reflexōes em torno do potencial de ação que está contido no "falar" que provoca uma motivação que leva ao "fazer" ou que, simplesmente, leva à inércia e à desmotivação das pessoas. Em uma obra conhecida, J.R. Searle (Speech Acts, 1969) reuniu e aprofundou estas reflexôes que têm sido incorporadas às propostas de inovação de gestão e planejamento na área social, como, por exemplo, a proposta do "Planejamento Estratégico Situacional”, de Carlos Matus. 
3. O termo "indústria" e a expressão correlata "sociedade industrial" na Teoria Crítica transcendem o significado usual e referem-se à generalização da racionalização, da homogeneização e da padronização que domina a vida cotidiana (Giroux, 1986).

\section{COMMUNICATION, CULTURE AND EDUCATIONAL ADMINISTRATION}

ABSTRACT: This article intents, from the reflections about the cultural industry and the industrial society, makes for philosophers of the Frankfurt School, to discuss the predominant model of administration of organizations and the possibility to mind an theory aid model of administration based on Communication Theory proposed in that School, and its application of renovate form on the educational organization.

Key words: Cultural Industry, Rationality, Organization, Communication, Educational Administration.

\section{Referências bibliográficas}

ADORNO, T. Dialética do Iluminismo. São Paulo: Tempo Brasileiro, 1978.

ADORNO, T. \& HORKHEIMER, M. “A Indústria Cultural”. In: Adorno et al., Teoria da Cultura de Massas, Editora Saga, 1969.

GIROUX, Henry. Teoria Crítica e resistência em educação. São Paulo: Vozes, 1986.

FAYOL, Henry. Administração geral e industrial, Editora Atlas, 1986.

GRIFFITHS, Daniel E. Teoria da administração escolar. São Paulo: Nacional, 1982.

HABERMAS, J. “Técnica e ciência enquanto ideologia”. In: Os Pensadores. $2^{a}$ ed., São Paulo: Abril Cultural, 1983.

LODI, João B. História da Administração. Editora Pioneira, 1982.

TANNEUBAUN \& SCHMIDT. Como escolher um modelo de liderança. São Paulo: MacGrill do Brasil, 1987.

TAYLOR, Frederick. Princípios da administração cientifica. São Paulo: Atlas, 1980. 